\title{
Is the Public Art Programme in the Ethekwini District, Kwazulu-Natal, Patient-Centred?
}

\begin{abstract}
Background: The South African public antiretroviral treatment (ART) programme was initiated in 2003 and is regarded as one of the largest in the world. This study provides a patient's perspective of the patient-centredness of the ART programme at four public hospitals in KwaZulu-Natal, South Africa.
\end{abstract}

Aim and setting: This study investigated respondents' interpretations of patientcentredness and whether they regarded the public Antiretroviral Treatment (ART) programme at four hospitals within the eThekwini District, KwaZulu Natal, South Africa as patient-centred and meeting their needs.

Methods: A mixed methods study was conducted at ARV clinics at four hospitals in eThekwini District, KwaZulu-Natal with 400 patients (selected sequentially) completing structured questionnaires and a further 12 patients participating in indepth interviews. All participants were patients who had accessed the programme for a minimum of one year and were 18 years and older.

Results: Given a choice of definitions of patient-centred care, the three most preferred by the patients who participated in the questionnaires were: it involves respectful care that takes the patients' needs, values, concerns expectations and preferences into account (53\%); it involved organising service provision around the patient (51.3\%) and it involves a respectful partnership between patients and healthcare workers and professionals (45.8\%). Whilst in-depth interviewed patients preferred: it involves a respectful partnership between patients and healthcare workers and professionals (83.3\%); it involves respectful care that takes the patients' needs, values, concerns, expectations and preferences into account $(66.8 \%)$ and it involves a holistic approach to patients' care and treatment (41.8\%). Of the patients who participated in the questionnaire $(98.5 \%)$ and of those interviewed $(75 \%)$ responded that the programme was not patient-centred.

Conclusion: Patients provided examples and their strong views regarding the lack of patient-centred care and made recommendations that could be implemented to change this.

Keywords: HIV/AIDS; Public ART programme; ARVS; Patient-centred; Patients

\author{
Research Article \\ Volume 5 Issue 1 - 2018 \\ Delarise Maud Mulqueeny* and Myra Taylor \\ Department of Public Health Medicine, University of KwaZulu- \\ Natal, South Africa \\ *Corresponding author: Delarise Maud Mulqueeny, \\ Department of Public Health Medicine, University of \\ KwaZulu-Natal, 409 Arnleigh, 186 Victoria Embankment, \\ Durban, 4001, South Africa, Tel: 27313072209 ; \\ Email: delarisemulqueeny@gmail.com
}

Received: May 11, 2017 | Published: January 29, 2018

\section{Introduction}

The South African public antiretroviral therapy (ART) programme was rolled out in 2004 and to date constitutes one of the largest ART programmes globally [1,2]. The programme has been hailed by many as a success due to the reduction in mortality and morbidity rates $[3,4]$. However, the success of any ART programme is dependent on consistent, effective supply and delivery of antiretrovirals (ARVs); a wide variety of drug options; efficient and effective staff, facility and administration; continuously improved diagnostics and technological advancement providing high-quality, easily accessible, service driven and comprehensive patient-centred care [5].

Patient-centred care is described as an innovative 'approach to the planning, delivery, and evaluation of health care that is grounded in mutually beneficial partnerships among health care providers, patients, and families' [6]. It further re-iterates the conceptual dimensions of the 'patient-as-person' and 'shared power and responsibility' as well as a 'therapeutic alliance' as described by Mead and Bower [7]. Healthcare that is patientcentred, respects and responds to patients' values and needs and embraces transformation, continuity, consistency, family and carer involvement, easy access to care, quality care and communication, information sharing, shared decision-making, respect, comfort and support [8].

Although patient-centred care has been the topic of much health research and debate during recent years, weaknesses and challenges regarding the process have been cited $[9,10]$. These include: no universally accepted definition, a focus predominantly on the biomedical model, many definitions existing and patients not being involved in developing the various definitions $[11,12]$. It is also used interchangeably with other terms such as 'patientcentred care', 'patient-centred approach', 'patient-centredness', 'person-centred' and 'patient-focused care' depending on which country and/or discipline is being discussed [13]. 
Although no universally accepted definition of patient-centred care exists, for the purpose of this paper the following definition will be assumed: Providing the care that a patient needs in the manner and at the time the patient desires [14]. Hence, an efficient patient-centred programme which focusses on the patient, continuous improvement of systems and processes, recruitment of quality staff, adherence and retention of patients is important to the success of an ART programme, as a link between patient- centredness and improved ARV adherence was found in a United States study $[15,16]$. Within the South African context many healthcare policies and guidelines promote effective patient care and one of the strategic objectives of The National Strategic Plan on HIV, STIs and TB 2012-2016 (NSP 2012-2016) is to 'Sustain Health' $[17,18]$. Therefore, as patients constitute the cornerstone of any public ART programme it is imperative for studies to investigate a patient-perspective of how patients interpret patient-centred care, whether they perceive the programme as patient-centred 11 years after the rollout and if it meets their needs. Hence, this study could fill a gap as few South African research studies highlight patients' involvement and evaluation of their treatment, medication and management of their ART journey.

\section{Objective}

The objective was to investigate patients' interpretation of patient-centredness and to ascertain if patients regard the public antiretroviral treatment (ART) programme at four urban hospitals within the eThekwini District, KwaZulu Natal, South Africa, as patient-centred and meeting the needs of patients.

\section{Research Methods and Design}

\section{Study design}

This study is part of a larger descriptive study which explored HIV sero-positive patients' experiences of the ART programme at ARV clinics based in four public hospitals and to establish what can be done to enable the ART programme to be patient-centred. For the purpose of this paper only the section on patient-centredness, from both the questionnaires and in-depth interviews (IDIs), will be addressed. This cross sectional design used sequential mixedmethods. The qualitative data was used to confirm quantitative data in order to attain a comprehensive overview and enhanced insight of patients' unique experiences and understanding of patient-centredness $[19,20]$. The design choice was based on the nature of the research questions, allowance for triangulation of methods and to achieve a comprehensive analysis of the results to reduce weaknesses and improve the strengths of utilising one approach with the ultimate aim being a synergistic outcome $[21,22]$.

\section{Study setting}

The study was conducted at the ARV clinics based in four public hospitals within the eThekwini District, KwaZulu-Natal, South Africa. KwaZulu-Natal hospitals were chosen as the province is known as the epicentre of the HIV epidemic [23].
The researcher is a patient at an ARV clinic in a public hospital and identifies with the socio-demographic characteristics of the study population. She informed all the gatekeepers about her role as a researcher.

\section{Study population and sampling strategy}

To obtain diverse patient perspectives, the study population was sourced from four ARV clinics based in different urban, geographical areas within the eThekwini district. The sample consisted of respondents of two sexes, different ages, ethnicity and sexual orientation who were recruited based on the inclusion criteria, that they were patients who were 18 years or older and had attended one of the four ARV clinics for a minimum of one year. Every fourth patient of the 400 participants (100 per ARV site) was systematically selected commencing with the first patient who arrived at the clinic. The sample for the questionnaire consisted of 239 females and 161 males. The in-depth interview (IDIs) respondents were purposively recruited and consisted of six females and six males [24] (Table 1).

Table 1: Key codes for socio-demographic characteristics of patients in in-depth interviews (IDIs).

\begin{tabular}{|c|c|c|c|}
\hline Key Code & Hospital & Gender & $\begin{array}{c}\text { Patient Interview } \\
\text { Number }\end{array}$ \\
\hline 1F1 & 1 & F=Female & 1 \\
\hline 1F2 & 1 & F=Female & 2 \\
\hline 1M3 & 1 & M=Male & 3 \\
\hline 2F4 & 2 & F=Female & 4 \\
\hline 2F5 & 2 & F=Female & 5 \\
\hline 2M6 & 2 & M=Male & 6 \\
\hline 3M7 & 3 & M=Male & 7 \\
\hline 3F8 & 3 & F=Female & 9 \\
\hline 3M9 & 3 & M=Male & 10 \\
\hline 4M10 & 4 & M=Male & 11 \\
\hline $4 M 11$ & 4 & M=Male & 12 \\
\hline $4 F 12$ & 4 & F=Female & \\
\hline
\end{tabular}

\section{Study instruments}

After consulting several patient-centred studies, questionnaires and surveys a questionnaire was developed by the primary investigator (PI) [25-27]. However, five sero-positive patients from the four sites, who tested the instrument, informed the researcher that they did not identify with the questions as they did not adequately address the unique set-up of the four clinics, their experiences, needs nor patients' interpretation of patient-centredness, but rather assumed a generic approach to the four clinics. Their input was similar to other studies which discussed patient-centred care $[28,29]$. After consultation with the second author, the pilot patients assisted the researcher 
compile a questionnaire containing nine definitions, which they felt patients would identify with and which would be easy for them to understand and complete. However, during the developmental and testing phase of the questionnaire, the pilot patients suggested a tenth option, 'None of the above'. This was added for participants who could not identify with the nine options. From those 10 options, respondents were required to choose three options that they felt best represented patient-centredness (Table $2 \& 3$ ) thus report on the results from the first question about patient- centredness.

As this paper reports on the results of two questions the second question addressed whether they regard the clinic that they attend as patient-centred, based on their interpretation of patient-centredness. Both the quantitative and qualitative instruments addressed the two questions similarly and both included respondents' personal information. However, the interview respondents also provided reasons for their answers in order to further explore the quantitative results and attain representative and comprehensive data whilst addressing the study aims.

\section{Data collection}

After full ethical clearance and permission from all four hospital managers was obtained, the data collection process commenced. As a sequential mixed-methods' design was employed, the 400 structured questionnaires were completed first and 12 in-depth, face-to-face interviews conducted thereafter with informed and consenting patients who were assured of confidentiality. The questionnaires were in English, hence the researcher and two trained trilingual research assistants, who were fully conversant in English, isiZulu and Afrikaans, were on hand to address any language translation challenges.

All the in-depth interview respondents were fully conversant in both English and isiZulu and they requested that the interviews led by DM be conducted in English. To address any language barriers or challenges that might occur during the interviews, the research assistants sat in on the interviews [30]. The in-depth interviews were conducted with the use of an interview schedule to allow for probes to access richer data and to pursue specific issues and themes raised by the participants [31]. Interviews continued until theoretical saturation whereby no more new data emerges from the sample [32]. The interviews were audiorecorded and lasted between one-and-a-half to two hours.

\section{Data analysis}

A sequential mixed analysis was used. The quantitative analysis was done prior to the qualitative data collection and analysis, to increase qualitative information and knowledge regarding patients' interpretation of patient-centredness and their opinion of whether the ARV clinic they attended, was patient-centred [33]. The quantitative data were captured using Epidata software and analysed using the Statistical Package for the Social Science (SPSS 22) software programme and descriptive data are presented.

The qualitative recordings were transcribed and a thematic coding technique was manually employed to identify themes and sub-themes [34]. The researcher read and reread the transcripts line by line, several times and coded the data using thematic analysis to identify differences and similarities in respondents' responses to ensure the credibility, dependability and trustworthiness of the data [35]. This was an ongoing process in order to address any information gaps. This allowed coding to evolve thereby embracing grounded theory analysis and constant comparative methods to allow deeper insight of the respondents' views [36].

\section{Ethical considerations}

The study received ethical approval from the Biomedical Research Ethics Committee (BFC089/15), permission from the KwaZulu-Natal Department of Health (HRKM 158/15) and the four hospital managers provided site clearance.

\section{Research rigour}

All questionnaires were checked prior to the patients leaving the site in order to avoid any question remaining unanswered and all questionnaires were checked daily for errors. Face validity was checked during the pilot [37].

Dual recording, face-to-face in-depth interviews, field and observation notes were data collection techniques used to ensure data triangulation. By piloting and then triangulating the data we aimed to ensure that the data from the questionnaire were valid and reliable, and that the in-depth interview data were credible and dependable [38]. The second author provided both quantitative and qualitative support and mentorship on an ongoing basis to ensure mixed-method rigour took place.

\section{Results}

The study was conducted between August and November 2015. In total 400 questionnaires and 12 interviews were administered at four sites and analysed. The results from both data collection tools are presented in Table $2 \& 3$ respectively. Both questionnaires and interviews respondents were required to choose three of ten options that they felt most embraced patient- centredness.

\section{Quantitative results $(n=400)$}

The three most selected options (Total $=600$ ) chosen by respondents amounted to half of the patients' responses. The second most popular option places patients squarely at the epicentre of service delivery which emphasises the positionality that patients require in their medical journey.

\section{Patients' responses as to whether or not the ART programme that they access, is patient-centred}

Only $6(1.5 \%)$ patients who completed the questionnaires, felt the ART programme was patient-centred and they all accessed treatment at hospital 3.

\section{Qualitative results ( $\mathrm{n}=12)$}

The three most selected options (Total $=23$ ) chosen by interviewed respondents amounted to more than half of the total responses. 
Table 2: Patients' three interpretations of patient-centredness of ten provided.

\begin{tabular}{|c|c|c|c|}
\hline Options & & $n=400$ & $\%$ \\
\hline $\begin{array}{l}\text { It involves respectful care that takes } \\
\text { the patients' needs, values, concerns, } \\
\text { expectations and preferences into account }\end{array}$ & Yes & 212 & 53 \\
\hline $\begin{array}{l}\text { It involves organizing service provision } \\
\text { around the patient }\end{array}$ & Yes & 205 & 51.25 \\
\hline $\begin{array}{l}\text { It involves a respectful partnership } \\
\text { between patients and healthcare workers } \\
\text { and professionals }\end{array}$ & Yes & 183 & 45.75 \\
\hline $\begin{array}{l}\text { It respects the uniqueness of patients } \\
\text { whilst placing patients' at the centre of } \\
\text { their care and treatment }\end{array}$ & Yes & 164 & 41 \\
\hline $\begin{array}{l}\text { It involves patients' rating the facility and } \\
\text { all the health care workers involved in } \\
\text { their treatment on a regular basis }\end{array}$ & Yes & 137 & 34.25 \\
\hline $\begin{array}{l}\text { It entails health care professionals } \\
\text { acknowledging that they don't always } \\
\text { have all the answers }\end{array}$ & Yes & 101 & 25.25 \\
\hline $\begin{array}{l}\text { It involves a move from "what's the } \\
\text { matter" with patients to "what matters' } \\
\text { to patients }\end{array}$ & Yes & 88 & 22 \\
\hline $\begin{array}{l}\text { It involves the active involvement and } \\
\text { engagement of patients and their families } \\
\text { in the design, implementation and } \\
\text { delivery of healthcare systems, support } \\
\text { and treatment that affects patients }\end{array}$ & Yes & 60 & 15 \\
\hline $\begin{array}{l}\text { It involves a holistic approach to patients' } \\
\text { care and treatment }\end{array}$ & Yes & 50 & 12.5 \\
\hline None of the above & Yes & 0 & 0 \\
\hline
\end{tabular}

The results from the first question reflect that more than half $n=212(53 \%)$ of the questionnaire respondents compared to $\mathrm{n}=8(66.75 \%)$ of the in-depth interview respondents interpreted the term patient-centred care as, 'It involves respectful care that takes the patients' needs, values, concerns, expectations and preferences into account'. Only one of the three options chosen by respondents who completed the questionnaires, differed from those chosen by in-depth interviewees and vice versa. Common to both the questionnaire and interviews results is a respectful attitude towards patients and a respectful patient-serviceprovider partnership.

\section{Reasons for respondents' interpretation of patient- centredness}

IDI respondents further provided reasons for selecting the three options that defined patient- centredness for them which are presented according to themes below:

Inclusion, representation, partnerships, involvement and engagement in decision making

Table 3: In-depth interview patients' three interpretations of patientcentredness of ten provided.

\begin{tabular}{|c|c|c|c|}
\hline Options & & $n=12$ & $\%$ \\
\hline $\begin{array}{l}\text { It involves a respectful partnership } \\
\text { between patients and healthcare workers } \\
\text { and professionals }\end{array}$ & Yes & 10 & 83.25 \\
\hline $\begin{array}{l}\text { It involves respectful care that takes } \\
\text { the patients' needs, values, concerns, } \\
\text { expectations and preferences into account }\end{array}$ & Yes & 8 & 66.75 \\
\hline $\begin{array}{l}\text { It involves a holistic approach to patients' } \\
\text { care and treatment }\end{array}$ & Yes & 5 & 41.75 \\
\hline $\begin{array}{l}\text { It respects the uniqueness of patients } \\
\text { whilst placing patients' at the centre of } \\
\text { their care and treatment }\end{array}$ & Yes & 4 & 33.25 \\
\hline $\begin{array}{l}\text { It involves the active involvement and } \\
\text { engagement of patients and their families } \\
\text { in the design, implementation and } \\
\text { delivery of healthcare systems, support } \\
\text { and treatment that affects patients }\end{array}$ & Yes & 3 & 25 \\
\hline $\begin{array}{l}\text { It involves patients' rating the facility and } \\
\text { all the health care workers involved in } \\
\text { their treatment on a regular basis }\end{array}$ & Yes & 1 & 8.25 \\
\hline $\begin{array}{l}\text { It involves a move from "what's the } \\
\text { matter" with patients to "what matters' to } \\
\text { patients }\end{array}$ & Yes & 2 & 16.75 \\
\hline $\begin{array}{l}\text { It involves organizing service provision } \\
\text { around the patient }\end{array}$ & Yes & 2 & 16.75 \\
\hline $\begin{array}{l}\text { It entails health care professionals } \\
\text { acknowledging that they don't always } \\
\text { have all the answers }\end{array}$ & Yes & 1 & 8.25 \\
\hline None of the above & Yes & 0 & 0 \\
\hline
\end{tabular}

The comments below demonstrate the extent to which patients want to be included in their medical journey. They also reflect the patients' commitment to their illness and their ability to articulate their need to be partners within the ART programme.

i) i1F1 Patients should be heard, seen and involved in everything affecting us. Like which treatment we take, how many times we come here, which clinic we would like to go to and what laws affect us... so they should ask for our opinion instead of always telling us what's right for us without understanding us.

ii) ii1F2 It has to mean we are in the middle of everything that affects us due to this virus. We must be asked our opinions... 
iii) iii2F5 All the things done to and for us should be good for us, our families and our health. We know our bodies and situation best and can help make these systems better if they involve us.

iv) iv4M10 Its the way patients are treated. Government and staff need to take us seriously so we should rate them so they know when they're good and when they're bad.

v) v4M11 We must be partners and work together to achieve it.

Patients emphasized the need for a partnership which meant a shared decision-making process between patients and the healthcare professionals thereby highlighting patients involvement and autonomy.

\section{Respect, relationships, communication and quality treatment} below:

The quality of service delivery is of concern to the respondents

i) IF2 Patients must feel comfortable to walk in here and know we're getting good care by good people who understand patients.

ii) $1 \mathrm{M} 3 \quad$ Patients are important to this clinic so we must be well taken care of.

iii) 3M7 It means better service and happy patients cause the better they treat us then we won't get sick so often.

iv) Communication skills are an important requirement within a patient-centred environment which is evident by the following:

v) 2F4 It's involves good communication, respect, professional and qualified staff, quality treatment that suits our needs.

vi) 3F8 It means speaking and listening to patients and also respecting us.

vii) The uniqueness and validation of patients' are highlighted in the quotes below.

viii) 3M9 All of us are different so this system must take that into account and treat us like human beings. There's a person behind our disease.

\section{Education, training and empowerment}

The quotes below are evidence of patients wanting to be empowered and the creation of an environment which promotes transparency, open communication and dialogue.

IM3 All the staff should explain to us what they're supposed to do so we know what to expect from them.

2M6 We need a system that empowers us to be better patients...

4F12 It means knowing everything that we should be told so that we're involved and if there is a mistake we can ask questions.

\section{Staff}

The need for positive patient-service provider relationships is reflected in the responses below:

3F8 Staff need to get to know us well so they know how to treat us and our opinions must be respected.

4F12 It is also having a bond with the staff so they know us and our needs and mostly respect us and we respect them so we live healthier lives.

\section{Needs}

Respondents expressed importance of their needs being understood as stated below:

i) $2 \mathrm{M} 6 \quad$... staff should go to classes to learn about patients' needs.

ii) 4M11 Government needs to understand what we need and make sure that they and professional staff give us what we need so we can live longer.

The above responses reflect patients' need to be actively involved in their treatment and not just passive participants in a paternalistic programme. They require respect, involvement, to be treated with dignity, receive information, actively participate and receive education, shared decision-making, acknowledgment, partnerships and empowerment. Respondents require their unique and fluid needs to be recognised and acknowledged.

\section{Respondents' responses as to whether or not the ART programme that they access, is patient-centred}

Respondents' interpretation of patient-centredness provided a premise for their decision regarding the reasons they provided regarding whether or not the clinic they attended was patientcentred. Hence, three (25\%) of the 12 patients who participated in the interviews felt the programme was patient-centred.

The results from the second question reflect that $n=6(1.5 \%)$, of the 400 questionnaire respondents (who were all from hospital 3 ), reported that their site was patient-centred compared to $n=3$ (25\%) of the 12 IDI respondents of which two were from Hospital 3 and one from Hospital 4.

Reasons why some respondents consider the programme patient-centred whilst others consider it lacking patient-centredness?

All 12 IDI respondents further qualified their choice of whether or not the ART programme they access, was patient-centred. Their input is divided into two sub-themed sections.

i) Namely those who articulated that the programme is patientcentred and

ii) Those who felt it lacked patient-centredness. 


\section{Public ART programme is patient-centred}

The three patients who felt the programme they accessed was patient-centred, provided reasons for their choice. These were assigned three themes namely education, training and empowerment; staff and infrastructure and processes.

\section{Education, training and empowerment}

The quality of health talks are highlighted below:

3F8 The health talks are good so I don't feel scared to talk.

A respondent perceived the health talks as 'good' which allowed her a comfort level to contribute. Such an environment could result in improved patients' knowledge base and empowering.

\section{Staff}

Respondents' mostly highlighted the positive disposition of staff below:

3M7Even though we sit outside waiting for the doors of the clinic to open I still feel strongly that our clinic is patient-centred as we have amazing staff here. They always start at $6 \mathrm{~h} 45$. The staff are on time and seem to love their work.

3F8 Yes of course it is. Everyone smiles and speaks well to the patients. Staff treat us very well here.

They felt staff were helpful; timeous; conscientious; passionate; friendly and spoke well to patients.

\section{Infrastructure and processes}

These respondents reported their satisfaction with the programme:

i) 3F8 We are allowed to choose our appointment dates so I can attend the clinic on a day that suits me.

ii) 4F12 I was really ill when I first came here and was saved so I must say this is a patient-centred clinic. I have not encountered any problems here. Everything is good.

The former quote indicates patients' involvement in their appointment dates which shows a patient-centred aspect to the appointment process. The latter quote describes the programme as life-saving which adds value to the programme's success in reducing morbidity and mortality rates. Worth noting was that the second respondent attended the clinic in the afternoon and did not have to sit outside whilst waiting for the clinic to open. Hence, that could be a reason for her not being affected by the open waiting area. Patients' responses regarding why they considered their ART programme as patient-centred highlight the positive relationships between patients and healthcare professionals and patient involvement, which is important in a patient-centred healthcare environment.

\section{Public ART programme lacks patient-centredness}

The other nine patients provided reasons for the programme they accessed not being patient-centred. These were assigned themes namely inclusion, representation, partnerships, involvement and engagement in decision-making; respect, relationships, communication and quality treatment; education, training and empowerment; staff, economic challenges; infrastructure and processes and unmet needs.

\section{Inclusion, representation, partnerships, involvement} and engagement in decision making

The following reflects respondents' perceptions that: staff lacked an understanding of patient-centred care, policy makers and staff did not request patients' input and that certain processes and departments were not patient-centred.

i) iIF1 We also have no power in what medication we are given, when our appointments are made or when it is convenient for us to attend this clinic. We're punished for being HIV+.

ii) 2F4 Patient-centredness-Haibo, I don't think these staff can spell that word so they definitely can't be. Government and the staff don't ask for our views.

iii) 3M9 No it is not, because the pharmacy is not patientcentred and no-one listens to our gripes about the pharmacy opening times. We need to be represented.

iv) 4M10 I feel like a voiceless, feeling-less person when I have to come to this clinic.

The responses further reflect respondents' challenges of feeling voiceless, powerless, receiving inadequate treatment as punishment for their status and their need to be represented and heard. The need for patients to be involved and empowered in their treatment and appointments are reported below:

\section{Respect, relationships, communication and quality treatment}

The responses below highlight respondents' perception of the treatment they receive:

i) 1F2 The clinic doors open at $7 \mathrm{~h} 30$ but the first patient is only seen to at $8 \mathrm{~h} 55$ because they are busy making tea, looking for bread, laughing and joking, mostly on their cell phones whether they taking your blood or updating your file while we just want to get out of here.

ii) $1 \mathrm{M} 3 \quad$ They do not respect patients. They just rude.

iii) 4M11 I am afraid to ask staff anything because we hardly ever get smiling, helpful responses. Instead it is frowns, loud voices and dismissals.

Such treatment includes negative staff attitudes, nonperformance of their duties during work hours, frivolous behaviour and respondents' need to be respected by staff.

\section{Education, training and empowerment}

The need for patients to be provided with information is reported below: 
2M6We are not provided with relevant information so we can understand our illness.

The above response could signify that health talks are not conducted regularly.

\section{Staff}

Staff challenges reported below pertain to the lack of staff supervision; staff's lack of understanding of patient- centredness; attitudes of staff and patients being nervous around staff.

1F1 It could never be, because staff are poorly supervised.

1 M3 The staff here have probably never heard of that thing, "patient-centred" because if they did, we would not be sitting here like nervous wrecks who can't wait to be seen and leave.

2F5 They have upgraded the clinic but forgot to upgrade the staff's attitudes.

Staff's attitudes and behaviour could be perceived as uncomfortable for patients. Hence it is core that the relational and interactional aspects of the journey for people living with HIV (PLHIV) are understood, strengthened and improved.

\section{Economic challenges}

Respondents reported financial challenges whilst accessing the public ART programme:

1F1 We have to pay for transport to come here so it does cost us.

3M7I only come here because I can't afford medical aid. If I could get a better job and have medical aid I would never come here to be treated this way as is it not good.

An improved job situation could result in a respondent joining a medical aid as he was not satisfied with the treatment he currently received.

\section{Infrastructure and processes}

The infrastructure and process challenges are reported below:

2M6We must wait in the cold while they're having their meetings which do not benefit us at all.

4M11 Twenty-one years into our democracy we are still sitting outside in the cold and heat with no thought to how inconvenient it is for us patients.

The facility and infrastructure challenges included poorly ventilated clinics which were not enclosed to suit the weather elements. A respondent did not perceive staff meetings as valueadding to patients.

\section{Unmet needs}

The responses below highlight that patients' needs are not being met:

2F5 Our needs are not met and as for patient-centred care, No.
2M6 Never ever, the staff don't even know what we need and want.

The respondent above added that staff did not understand patients' needs and wants.

In summary, patients' challenges included: being voiceless, fearful, powerless, poor relationships and interactions with staff, feelings of exclusion and not having much input regarding their appointments and medical treatment. Further, they were not consulted in decision-making regarding their medical journey. The responses indicate that patients are observant and are able to articulate their frustrations and mostly negative feelings about the care and treatment that they receive. Patient-centred care showcases the person behind the patient, so by providing a comprehensive understanding and engagement of each person's self-worth within the healthcare setting, the results highlight the negative affect the programme has on them.

\section{Discussion}

This section comprises a combined discussion on patients' interpretation of patient- centredness, whether or not they regard the programme as patient-centred and reasons why they considered it so:

\section{Inclusion, representation, partnerships, involvement and engagement in decision making}

Current studies mostly highlight the passive role that PLHIV play in their own medical journey rather than their multidimensional needs which inform patient-centred care $[39,40]$. However, respondents reported the need to be heard, represented and involved in shared decision-making processes to feel validated, 'nothing about me without me' [41].

\section{Respect, relationships, communication and quality treatment}

As customers are important to any business, patients should be important and core to the ART programme. Therefore similar to any business model, the satisfaction and retention of patients is key to the public programme, as the ability to engage and retain patients results in the success of the ART programme. ${ }^{42}$ However despite changes to eligibility criteria, down-referral and transfers out to clinics, respondents still feel that they are not at the centre of their treatment journey and have to be compliant out of fear of rebuttals from staff. One patient viewed the inadequate service delivery as a form of punishment for being HIV sero-positive [42].

The respondents' interpretation of patient-centredness validate why they perceive their clinics as lacking patientcentredness. The results do not reveal respondents' opinions of the impact of government's various HIV counselling and testing (HCT) drives and the decision to start all people who test HIV positive on ARVs. However, this could increase the number of people accessing the programme which could affect an already overburdened healthcare system and further strain service delivery [43]. 
Elements such as relationship building and interactional relationships are cited as essential but time-consuming for patient-centred care, as they promote empowerment and engagement of patients and healthcare workers [44]. However, the majority of respondents highlighted a lack of these elements. Although relationship building and interactional relationships are not documented as stand-alone items in the ten options - key words, phrases and terms are present in the three most chosen options that patients felt represented patient-centredness and the reasons therefore. These are patients' needs, concerns, expectations and preferences; within a respectful partnership between patients and healthcare workers and professionals and within a holistic approach to patient care and treatment. Further these are similar to the primary components of the International Alliance of Patients' Organization's (IAOPA), definition of patientcentred care which highlights the need to include patients' wants, needs, values and preferences [45].

Further, the results of this study highlighted poor patientprovider relationship which concurs with the findings of another study which found that patients' 'dissatisfaction came from experiences with abrupt, rude and/or disrespectful providers' [46]. These results highlighted the poor service delivery which confirmed similar reports by Lambdin et al. (2011) [47].

\section{Education, training and empowerment}

Continuous improvement to existing systems and staffs' as well as patients' knowledge bases is an empowerment strategy for all human capital involved in the ART programme. It could also enhance job satisfaction and PLHIV's quality of life [48].

\section{Staff}

This study's results concur with a Cape Town study about the perceptions and experiences of HIV-positive individuals when accessing treatment and sexual and reproductive health (SRH) services. That study found that some respondents were exposed to disrespectful staff, 'staff shortages, long queues and lengthy waiting time' [49]. For the public ART programme to enjoy increased success requires a right fit entailing both healthcare professionals and patients flourishing in a warm, nurturing environment. Therefore healthcare professionals and the healthcare system cannot be overlooked as patient care and support is compromised if they are not part of the patient-centred process.

\section{Economic challenges}

The supply of ARVs to patients is free. However, the costs of attending the ARV clinic involves transportation costs which may pose a financial burden to some patients. This is similar to a Turkish study's findings which linked finance challenges to adherence and retention [50]. However, it is dissimilar to patients in some parts of India who receive a travelling allowance to fetch their ARVs [51]. However, eThekwini respondents do not receive the same.

\section{Infrastructure and processes}

Patient dissatisfaction can result in non-adherence, loss to follow-up and patients' defaulting [52]. Certain aspects of these challenges highlighted by patients can be resolved at the clinic/ hospital. However, improvements to infrastructure such as enclosed facilities have budgetary and financial implications which have to be resolved by government and/or sponsorship programmes.

\section{Unmet needs}

People living with HIV (PLHIV) have many needs. These may include psychosocial, economic, mental health, sexual, spiritual and reproductive needs [51,53]. Respondents highlighted that their needs were not being met and most staff do not understand their needs.

In conclusion, this study provided a medium for patients to describe their interpretation of patient-centred care and articulate if their ARV clinic was patient-centred The results highlight the need for the programme to move towards patientcentred care which could increase patient retention, adherence and satisfaction, promote shared decision-making and cement patient-provider relationships [54]. These results concur with a South African study which focussed on why ART patients default [5]. The mixed method design rendered rich data as the quantitative data provided the numerical description and the qualitative data complemented the results with patients' lived experiences [55]. The patients' responses to the quantitative questions were then explored further in the in-depth interviews to enhance the validity and reliability of the study results. It provided a broader view of patients understanding of patientcentredness; the reasons why they perceive the public ART programme at various sites as patient-centred and whether their needs are being met.

\section{Relevance}

This study could assist healthcare workers, clinic supervisors and policy makers to understand the manner in which patients perceive patient-centred care and the reasons for them experiencing the four ART programmes as patient-centred or not. It could further assist the management, healthcare workers and patients to forge patient-centred relationships which would benefit all programme stakeholders.

\section{Recommendations}

Patients should be included in planning, designing and evaluating ART programmes. Patient-centred intervention strategies could be formulated to improve the quality of patient care locally, provincially and nationally as well. Staff should attend patient-centred workshops and training to have a comprehensive understanding of the concept. More patient- involved studies should take place for a greater understanding of the needs of patients which could result in a universally accepted definition of the concept. HIV sero-positive researchers should disclose their status within their studies to assist with destigmatisation and provide role-modelling for infected people. Dialogue sessions between patients and staff could improve the situation. Collaborations by the private and public sectors, support groups, community based organisations and government can also assist to realise these needs. Such efforts will improve the lives of PLHIV. 
The study results necessitate the need for further investigation and improvement of systems, processes and relationships to ensure that the care and service provision is patient-centred.

\section{Limitations}

Healthcare professionals and policy makers were not included in this patient perspective study, hence their input could have yielded a broader study with all stakeholders being represented. More sites and patients could have been included to attain a more comprehensive result of patients' experiences of patientcentredness. As the PI is HIV sero-positive and accessed one of the study sites she was constantly aware of her dual positionality being an insider performing an outsider function in the study. Such positionality could potentially result in bias. Use of a journal and self-reflection were tools used during the data collection and analysis process to ensure this did not impact on the study. Although the questionnaire was developed by patients and piloted it could be developed further to clarify patient-centred care concepts. Addressing all the respondents' unmet needs and challenges might not be met at the clinic level and would have to be referred to province or national departments, which could be a time-consuming process.

\section{Conclusion}

Few of the study respondents considered the ARV clinic they attended to be patient-centred, or that their needs were being met based on their interpretation of the concept. This highlights the importance of regularly investigating patients' perspectives of how they interpret the care and treatment which they receive at the ARV clinics that they attend, in order to ascertain whether their needs are being met and whether service delivery is on a par with the protocols and legislation or mere rhetoric. This study placed patients' experiences, interpretations, expectations and needs at the forefront to draw attention to the importance of an engaged, evolving client paradigm to prioritise patient-centred care.

\section{Acknowledgement}

None.

\section{Conflict of Interest}

None.

\section{References}

1. Moorhouse M (2014) Closer to zero: Reflections on ten years of ART rollout. SAMJ 15(1): 9.

2. Evans D (2013) Ten years on ART - where to now? SAMJ 103(4): 229230

3. Johnson LF (2012) Access to antiretroviral treatment in South Africa, 2004-2011. SAJHIVMED 13(1): 1-25.

4. Nattras N (2006) South Africa's 'Rollout' of Antiretroviral Treatment: A Critical Assessment. JAIDS 43(5): 618-623.
5. Miller CM, Kethapile M, Rybasack-Smith H, Rosen S (2010) Why are antiretroviral treatment patients lost to follow-up? A qualitative study from South Africa. Trop Med Int Health 15(s1): 48-54.

6. www.ipfcc.org/pdf/CoreConcepts.pdf.

7. Mead N, Bower P (2000) Patient-centredness: a conceptual framework and review of the empirical literature. Social Science \& Medicine. 51(7): 1087-1110.

8. Shaller D (2007) Patient-centred care: what does it take? The Commonwealth Fund, USA, p. 1-34.

9. Clay AM, Parsch B (2016) Patient-and Family-Centered Care: It's Not Just for Paediatrics Anymore. AMA Journal of Ethics 18(1): 40-44.

10. Groene $O$ (2011) Patient centredness and quality improvement efforts in hospitals: rationale, measurement, implementation. Int J Qual Health Care 23(5): 531-537.

11. Pelzang R (2010) Time to learn: understand patient-centred care. BJN 19(14): 912-917.

12. Robinson JH, Callister LC, Berry JA, Dearing KA (2008) Patientcentred care and adherence: Definitions and applications to improve outcomes. J Am Acad Nurse Pract 20(12): 600-607.

13. Jayadevappa R, Chhatre S (2011) Patient-centred Care-A conceptual model and review of the state of art. TOHSPJ 4:15-25.

14. Davis K, Schoenbaum SC, Audet AM (2005) A 2020 vision of patientcentered primary care. J Gen Intern Med 20(10): 953-957.

15. Vawda YA, Variawa F (2012) Challenges confronting health care workers in government's ARV rollout: rights and responsibilities. PER 15(2): 1-36.

16. Nelsen A, Gupta S, Trautner BW, Petersen NJ, Garza A, at al. (2013) Intention to adhere to HIV treatment: A patient-centred predictor of antiretroviral adherence. HIV Med 14(8): 472-480.

17. Serenata C (2010) Changes to the ART guidelines - An overview. Southern African Journal of HIV Medicine 11(1): 28.

18. (2002) The Patients' Rights Charter, Department of Health, UK, p. $1-3$.

19. Creswell JW, Plano Clark V (2007) Designing and Conducting Mixed Methods Research, Thousand Oaks, USA.

20. Morgan DL (2006) Connected contributions as a motivation for combining qualitative and quantitative methods. In: Curry L, Shield R, et al. (Eds.), Improving Aging and Public Health Research: Qualitative and Mixed Methods. American Public Health Association and Gerontological Society of America, DC, USA, pp. 53-63.

21. Creswell JW (2013) Steps in conducting a scholarly mixed methods study. DBER Speaker Series, USA, p. 1-54.

22. Curry A, Nembhard IM, Bradley EH (2009) Qualitative and Mixed Methods Provide Unique Contributions to Outcomes Research. Circulation 119(10): 1442-1452.

23. Kiepiela P, Manasa J, Moosa MY, Moodley P, Gordon M, et al. (2014) HIV Drug Resistance Patterns at the Epicentre of the HIV-1 Epidemic in Kwazulu-Natal, South Africa 2003-2013. J AIDS Clin Res 5(5): 299.

24. Fugard AJB, Potts HWW (2015) Supporting thinking on sample sizes for thematic analyses: a quantitative tool. International Journal of Social Research Methodology 18(6): 669-684. 
25. Hudon C, Fortin M, Haggerty JL, Lambert M, Poitras ME (2011) Measuring Patients' Perceptions of Patient-Centered Care: A Systematic Review of Tools for Family Medicine. Ann Fam Med 9(2): 155-164.

26. Epstein RM, Franks P, Fiscella K, Shields CG, Meldrum SC (2005) Measuring patient-centered communication in patient-physician consultations: theoretical and practical issues. Soc Sci Med 61(7): 1516-1528.

27. Mercer SW, Howie JG (2006) CQI-2--a new measure of holistic interpersonal care in primary care consultations. $\mathrm{Br} \mathrm{J}$ Gen Pract 56(525): 262-268.

28. Cliff B (2012) The Evolution of Patient-Centered Care. Journal of healthcare management 57(2): 86-88.

29. Scambler S, Gupta A, Asimakopoulou K (2015) Patient-centred care what is it and how is it practised in the dental surgery? Health Expect 18(6): 2549-02558.

30. Squires A (2008) Language barriers and qualitative nursing research: methodological considerations. Int Nurs Rev 55(3): 265-273.

31. Gill P, Stewart K, Treasure E, Chadwick B (2008) Methods of data collection in qualitative research: interviews and focus groups. British Dental Journal 204: 291-295.

32. Mason M (2010) Sample Size and Saturation in PhD Studies Using Qualitative Interviews. Forum: Qualitative Social Research 11(3):

33. Curry A, Nembhard IM, Bradley EH (2009) Qualitative and Mixed Methods Provide Unique Contributions to Outcomes Research. Circulation 119(10): 1442-1452.

34. Braun V, Clarke V (2006) Using thematic analysis in psychology. Qualitative Research in Psychology 3(2): 77-101.

35. Onwuegbuzie AJ, Combs JP (2011) Data Analysis in Mixed Research: A Primer. International Journal of Education. 3(1): 1-25.

36. Lawrence J, Tar U (2013) The use of Grounded Theory Technique as a Practical Tool for Qualitative Data Collection and Analysis. Electronic Journal of Business Research Methods 11(1): 29-40.

37. Holden RR (2010) Face Validity. Corsini Encyclopedia of Psychology $1-2$.

38. Leung L (2015) Validity, reliability, and generalizability in qualitative research. J Family Med Prim Care 4(3): 324-327.

39. Côté J, Godin G, Guéhéneuc YG, Genevieve Rouleau, Pilar RamirezGarcia, et al. (2012) Evaluation of a real-time virtual intervention to empower persons living with HIV to use therapy self-management: study protocol for an online randomized controlled trial. Trials 13: 187.

40. Hoa DM (2011) Antiretroviral Therapy (ART) Adherence among People Living with HIV/AIDS (PLHIV) in the North of Vietnam: A Multi-method Approach. PhD Thesis School of Public Health, Faculty of Health and Institute of Health and Biomedical Innovation, Queensland University of Technology, Australia, pp.1-268.

41. Kunneman M, Montori VM (2016) When patient-centred care is worth doing well: informed consent or shared decision-making. BM] Quality \& Safety, UK, p.1-4.
42. Horstmann E, Brown J, Islam F, Buck J, Agins BD (2010) Retaining HIV-Infected Patients in Care: Where Are We? Where Do We Go from Here? CID 50(5): 752-761.

43. Mathibe M, Hendricks S, Bergh A (2015) Clinician perceptions and patient experiences of antiretroviral treatment integration in primary health care clinics, Tshwane, South Africa. Curationis 38(1).

44. Dow B, Haralambous B, Bremner F, Fearn M (2006) What is personcentred healthcare? A literature review. Melbourne: Victorian Government Department of Human Services and National Ageing Research Institute.

45. (2007) What is Patient-Centred Health Care? A Review of Definitions and Principles. ( $2^{\text {nd }}$ edn), International Alliance of Patients' Organizations, UK, p.1-37.

46. Osborne M, Obermeyer CM (2016) Understanding client satisfaction with HIV testing and counselling services: a mixed-methods study in four African countries. AIDS Care 28(6): 689-694.

47. Lambdin BH, Micek MA, Koepsell TD, Hughes JP, Sherr K, et al. (2011) Patient Volume, Human Resource Levels, and Attrition from HIV treatment programs in central Mozambique. J Acquir Immune Defic Syndr 57(3): 33-39.

48. Degroote S, Vogelaers D, Vandijck DM (2014) What determines health-related quality of life among people living with HIV: an updated review of the literature. Arch Public Health 72(1): 40.

49. Orner P, Cooper D, Myer L, Zweigenthal V, Bekker L, et al. (2008) Clients' perspective on HIV/AIDS care and treatment and reproductive health services in South Africa. AIDS Care 20(10): 1217-1223.

50. Kose S, Mandiracioglu A, Mermut G, Kaptan F, Ozbel Y (2012) The Social and Health Problems of People Living with HIV/AIDS in Izmir, Turkey. Eurasian J Med 44(1): 32-39.

51. Dixit S, Bhagwat AK, Raghunath D, Taneja G (2009) Evaluation of the Needs of People Living with HIV/AIDS in Selected Districts of State of Madhya Pradesh, India: Findings from a Preliminary Study. OJHAS 8(2): 1-7.

52. Andaleeb S, Siddiqui N, Khandakar S (2007) Patient satisfaction with health services in Bangladesh. Health Policy Plan 22(4): 263-273.

53. Pretorius L, Gibbs A, Crankshaw T, Willan S (2015) Interventions targeting sexual and reproductive health and rights outcomes of young people living with HIV: a comprehensive review of current interventions from sub-Saharan Africa. Glob Health Action 2(8): 28454.

54. Mead N, Bower P (2000) Patient-centredness: a conceptual framework and review of the empirical literature. Soc Sci Med 51(7): 1087-1110.

55. Bentahar 0, Cameron R (2015) Design and Implementation of a Mixed Method Research Study in Project Management. The Electronic Journal of Business Research Methods 13(1): 3-15. 